\title{
PEMROSESAN SINYAL ANALOG AUDIO VIDEO UNTUK TRACKING ANTENNA SYSTEM PADA SET TOP BOX DVB-T2
}

\author{
Herti Miawarni \\ Fakultas Teknik, Program Studi Teknik Elektro \\ Universitas Bhayangkara Surabaya \\ Email: herti_mia@ubhara.ac.id \\ Dwi Edi Setyawan \\ Fakultas Teknik Elektro, Program Studi Teknik Komputer \\ Institut Teknologi Telkom Surabaya \\ Email: ediset@ittelkom-sby.ac.id \\ Eko Setijadi \\ Fakultas Teknologi Elektro, Program Studi Teknik Elektro \\ Institut Teknologi Sepuluh Nopember Surabaya \\ Email: ekoset@ee.its.ac.id
}

\begin{abstract}
ABSTRAK
Penelitian ini membahas tentang tracking antenna system dengan kemampuan auto-tracking yang didesain untuk Set Top Box DVB-T2. Tracking antenna system membutuhkan parameter input yang harus didapat secara plug and play. Sinyal analog video dan audio diusulkan untuk dapat digunakan sebagai parameter input bagi tracking antenna system. Sinyal analog audio dan video kemudian diolah agar dapat mendeskripsikan dan membedakan kondisi freeze maupun kondisi normal. Uji coba karakteristik sinyal analog audio dan video dilakukan untuk memastikan kelayakan sebagai parameter input bagi tracking antenna system. Penelitian ini meliputi desain sistem, realisasi dan uji coba. Hasil uji coba menunjukan bahwa sinyal analog audio dan video layak digunakan sebagai parameter input bagi tracking antenna system. Hal ini dibuktikan dari uji coba karakteristik dan uji coba pada blok analog signal processing yang menunjukan adanya perbedaan nilai ADC secara signifikan baik saat kondisi freeze maupun kondisi normal.
\end{abstract}

Kata kunci: tracking antenna system; DVB-T2; set top box; pemrosesan sinyal analog; audio video.

\begin{abstract}
This study discusses the tracking antenna system with auto-tracking capabilities that designed for DVB-T2 Set Top Boxes. Tracking antenna system requires input parameters that must be obtained by plug and play. Video and audio analog signals are proposed to be used as input parameters for system antenna tracking. Audio and video analog signals are then processed so that they can describe and distinguish between freeze conditions and normal conditions. characteristics trials of analog audio and video signals to ensure the feasibility of being an input parameter for system antenna tracking. This study includes system design, realization, and trial. The results of the trial show that analog audio and video signals are suitable to be used as input parameters for system antenna tracking. This is evidenced by the characteristic trials and trials on analog signal processing blocks which show a significant difference in $A D C$ values both during freeze and normal conditions.
\end{abstract}

Keywords: tracking antenna system; DVB-T2; set top box; analog signal processing; audio video.

\section{PENDAHULUAN}

Teknologi siaran TV di Indonesia mulai berpindah menuju teknologi digital. Umumnya, perangkat TV yang ada di masyarakat belum support untuk berpindah ke teknologi DVB-T2 (Digital Video Broadcasting-Second Generation Terrestrial). Untuk dapat menerima siaran TV digital, masyarakat harus menggunakan DVB-T2 STB (Set Top Box) yang banyak dijual di pasaran. Dalam penggunaan DVB-T2 STB, ketepatan arah antena adalah salah satu faktor yang berpengaruh besar terhadap kualitas video pada layar TV. Ketidaktepatan arah antena dapat menimbulkan loss signal dan freeze pada layar TV.

Tujuan dari penelitian ini adalah, untuk membangun tracking antenna system yang memiliki kemampuan auto tracking. Dalam hal ini, sistem memungkinkan antena untuk berputar arah secara 
otomatis hingga mencapai arah antena yang tepat. Sementara fokus pada penelitian ini membahas tentang usulan, desain dan realisasi metode pemrosesan sinyal analog audio \& video agar dapat digunakan sebagai parameter input yang handal.

Tracking antenna system tentu saja membutuhkan parameter input. Dalam penelitian ini, parameter input diambil dari sinyal analog audio dan video yang didapat dari panel utilitas perangkat STB. Adapun alasan untuk menggunakan parameter ini adalah, sinyal audio dan video selalu tersedia pada setiap produk STB yang ada dipasaran. Sehingga diharapkan tracking antenna system yang dibangun dapat bersifat plug and play dengan berbagai merk atau produk perangkat STB. [1]. CIR diimplementasikan dalam proses pemantauan kualitas penerimaan saluran kanal DVB-T2 [2], [3]. Analisa sederhana Bit Error Rate (BER) juga pernah diusulkan pada antena khususnya Mobile Digital Television[4]. Dua metode tersebut akan sangat sulit diimplementasikan jika tracking antenna system yang dibangun dituntut dapat plug and play dengan perangkat STB. Tracking antenna system berbasis pemrosesan sinyal analog video CVBS (Composite Video Baseband Signal) pernah diusulkan pada perangkat STB DVB-T2 [5]. Metode yang diusulkan pada penelitian tersebut bersifat semi plug and play karena menggunakan signal indicator sebagai parameter tambahan, sehingga perlu melakukan modifikasi minor pada utilitas STB. Dengan mengadopsi metode tersebut, maka pada penelitian ini, parameter yang dipilih adalah sinyal analog video yang memiliki format sinyal CVBS. Adapun parameter input tambahan adalah sinyal analog audio sebagai pengganti signal indicator. Sehingga pada penelitian ini, parameter input tracking antenna system yang dapat digunakan adalah sinyal analog audio dan video.

\section{METODOLOGI PENELITIAN}

Untuk merealisasikan fokus penelitian, metodologi penelitian dilakukan melalui 3 tahap seperti pada Gambar 1. Tahap pertama adalah berkaitan dengan desain sistem. Tahap kedua adalah berkaitan dengan realisasi dalam prototype. Tahap ketiga adalah berkaitan dengan uji coba, hasil dan pembahasan.

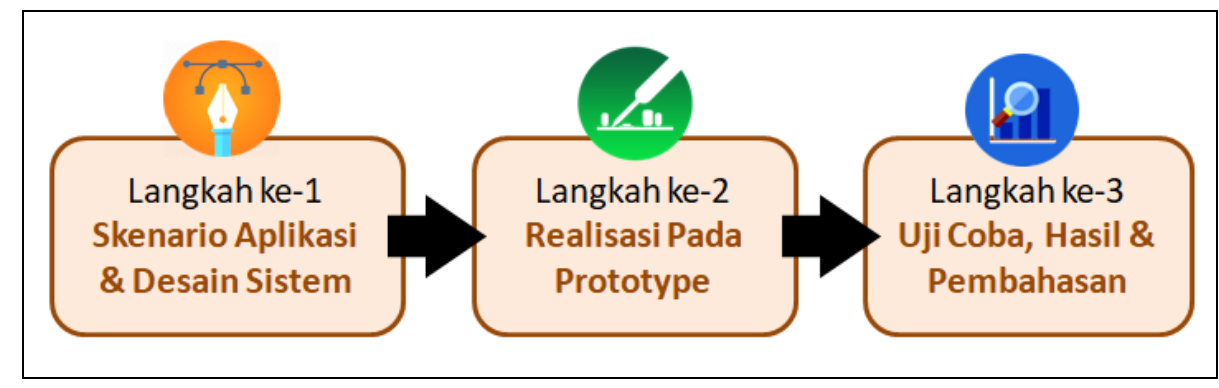

Gambar 1. Metodologi Penelitian

\subsection{Skenario Aplikasi dan Desain Sistem}

Skenario aplikasi mendeskripsikan pengunaan tracking antenna system pada lingkungan yang sebenarnya. Pembahasan yang ada pada paper ini mengacu pada konfigurasi peralatan yang ditunjukan oleh Gambar 2. Koneksi audio video terhubung oleh AV-in pada perangkat televisi konvensional dan terhubung juga ke tracking antenna sistem yang dibangun. Antenna yang digunakan pada sistem adalah jenis antena indoor, sehingga batasan pembahasan hanya pada penerimaan siaran TV pada lingkungan indoor. Antena pada sistem terhubung ke RF-in pada DVB-T2 STB. Dengan demikian, antara DVB-T2 STB dengan sistem membentuk hubungan close loop. 


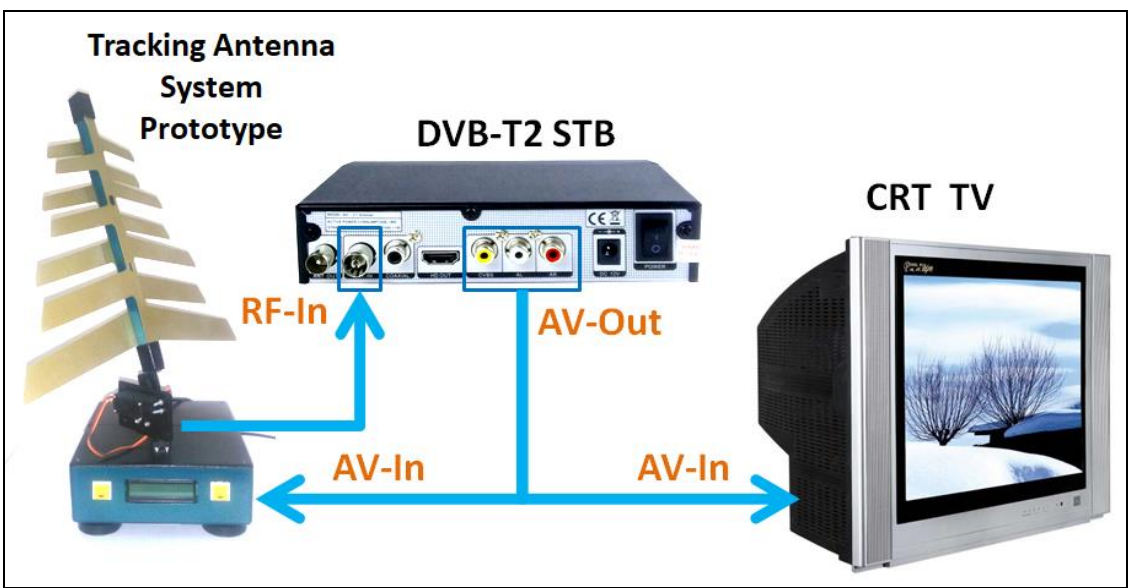

Gambar 2. Skenario Aplikasi

Desain sistem mendeskripsikan struktur diagram blok pada tracking antenna system yang dibangun dari beberapa bagian. Antara lain adalah: Pemrosesan sinyal analog audio dan video, freeze detector, decision maker, servo motor, servo motor driver dan antenna indoor. Secara detail, desain system seperti yang terlihat pada Gambar 3. Sementara, fokus pembahasan pada paper ini dibatasi hanya pemrosesan sinyal analog audio dan video.

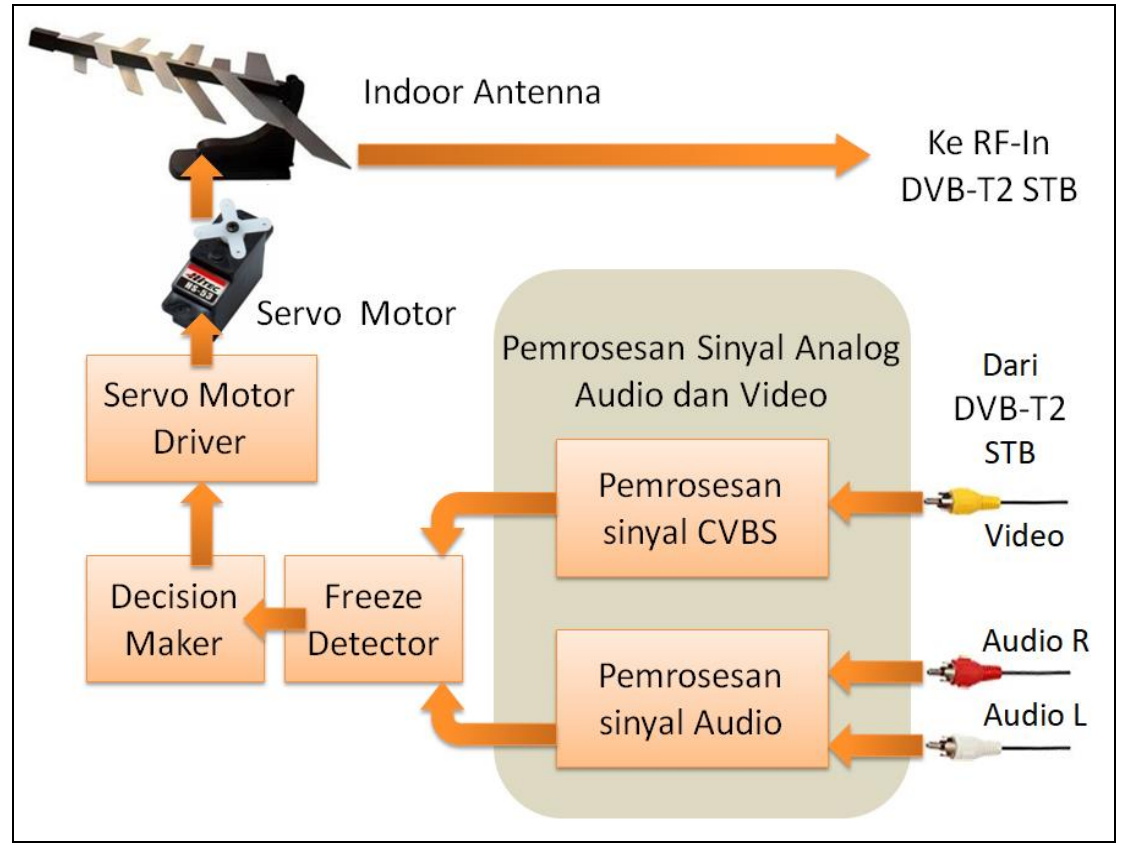

Gambar 3. Desain Sistem

\subsection{Pemrosesan Sinyal Analog Audio dan Video}

Secara umum, pemrosesan sinyal analog audio dan video pada AV-Out bertujuan untuk mendapatkan parameter input bagi tracking antenna system. Secara khusus, system membutuhkan informasi terjadinya freeze. Informasi ini dapat diketahui dari sinyal video dan audio pada AV-Out DVBT2 STB. Untuk menghemat komputasi, pengolahan kedua sinyal dilakukan secara analog.

Pada sinyal video, fenomena freeze ditandai dengan terjadinya still atau video tak bergerak. Sementara pada sinyal audio, fenomena freeze ditandai dengan suara yang konstan atau bahkan bisu. Pada saat terjadi freeze, koneksi AV-Out (Video-Out) akan mengeluarkan sinyal CVBS dengan level luminan dan krominan yang konstan hingga freeze berhenti. Sementara koneksi AV-Out (Audio-Out) akan mengeluarkan sinyal audio dengan level yang relatif konstan pula. Dengan demikian, level sinyal audio dan video menjadi fokus utama proses pengolahan sinyal. 
Pada penelitian ini, pemrosesan sinyal analog audio dan video dibangun dari gabungan antara rangkaian amplifier sebagai pengkondisi sinyal dan ADC (Analog to Digital Converter). Level audio dan video diukur oleh blok level meter dan kemudian dikonversi menjadi data digital oleh ADC agar bisa diolah oleh microcontroller. Dalam realisasi, desain system menggunakan 3 channel ADC. ADC 0 dan ADC 1 digunakan untuk sinyal audio left dan right. Sementara ADC 2 digunakan untuk sinyal video. Secara fisik, ketiga channel ADC telah terintegrasi pada microcontroller AT-Mega 32 A.

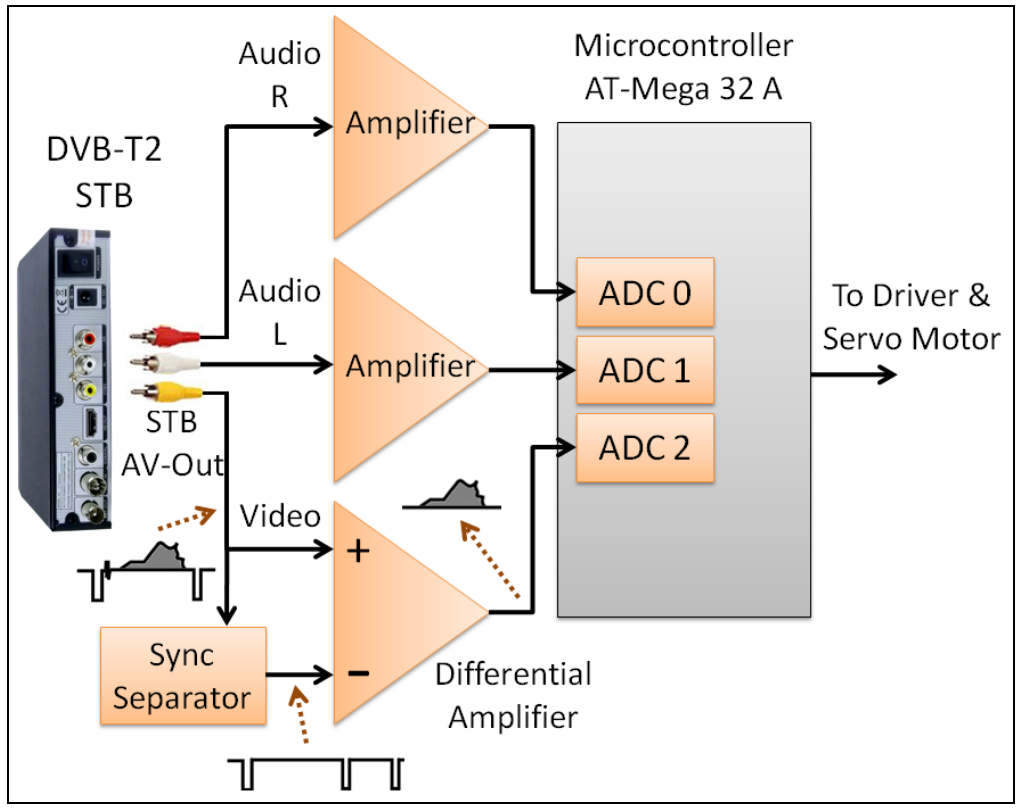

\section{Gambar 4. Diagram Blok Pemrosesan Sinyal Analog Audio dan Video}

Gambar 4 menunjukan diagram blok pemrosesan sinyal. Rangkaian sync separator, differential amplifier dan ADC 2 digunakan untuk mengolah sinyal video. Dalam hal ini, ADC berfungsi mengkonversikan sinyal luminance dan chrominance menjadi data digital. Sementara amplifier, ADC 0 dan ADC 1 berfungsi untuk menguatkan sinyal audio dan kemudian mengubahnya menjadi data digital.

\section{HASIL DAN PEMBAHASAN}

\subsection{Karakteristik Sinyal CVBS}

Tujuan dari uji coba ini adalah untuk mengetahui karakteristik sinyal CVBS pada kondisi normal dan kondisi freeze. Uji coba dilakukan dengan cara melakukan pengamatan menggunakan oscilloscope. Gambar 5 menunjukan metode uji coba. Dalam metode uji coba, Antena indoor dihubungkan dengan koneksi RF-input pada DVB-T2 STB. Output video pada DVB-T2 STB dihubungkan ke koneksi AV-In pada panel belakang televisi. Sementara AV-Out dihubungkan dengan probe oscilloscope. Arah antenna diubah secara manual untuk mensimulasikan kondisi normal dan kondisi freeze. Gambar 6 menunjukan realisasi dan proses uji coba, sementara hasil uji coba ditunjukan pada Tabel 1.

Sinyal analog CVBS terdiri dari beberapa sinyal antara lain adalah, luminance signal, chrominance signal, synchronization pulse dan burst signal. Pada penerima TV analog, karakteristik seluruh sinyal tersebut dapat dipengaruhi oleh kejernihan atau kualitas video. Namun pada penerima TV digital, hal tersebut tidak terjadi. Hal ini dapat dilihat dari hasil uji coba pengamatan menggunakan oscilloscope. Dalam hal ini, tidak ada perbedaan karakteristik antara kondisi video saat freeze maupun normal. 

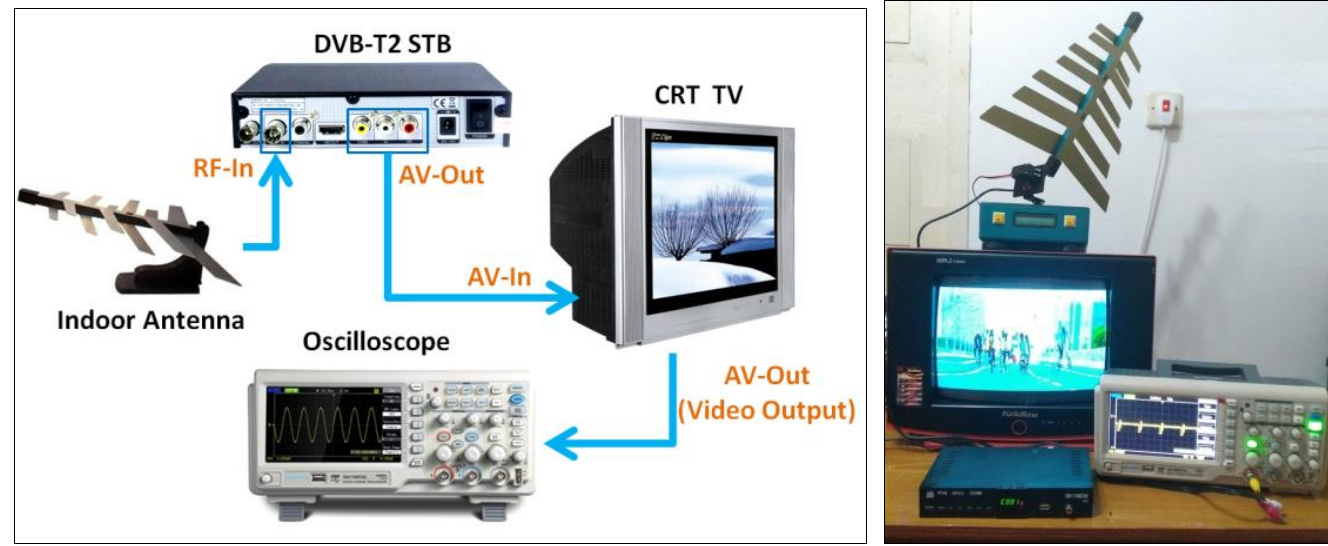

Gambar 5. Metode Uji Coba

Gambar 6. Realisasi dan Proses Uji Coba

Tabel 1. Hasil uji coba karakteristik sinyal CVBS

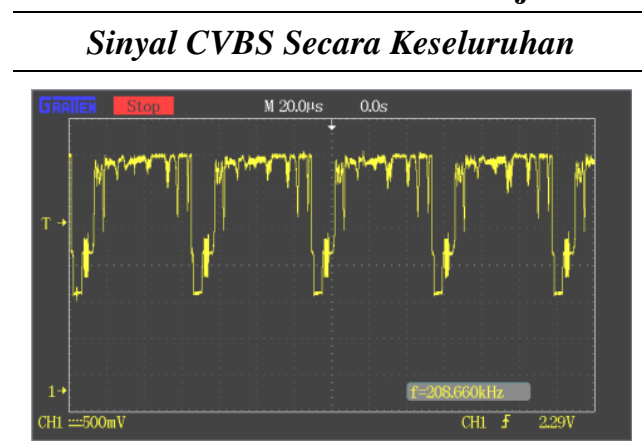

Sinyal CVBS saat kondisi freeze maupun normal

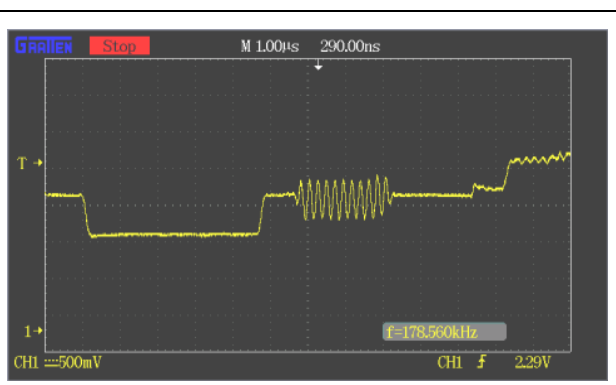

Pulsa Sinkronisasi dan Burst saat kondisi freeze maupun normal

\subsection{Karakteristik Sinyal Audio}

Tujuan dari uji coba ini adalah untuk mengetahui karakteristik sinyal audio pada kondisi normal dan kondisi freeze. Seperti pada uji coba sebelumnya, Uji coba ini dilakukan dengan cara melakukan pengamatan menggunakan oscilloscope. Gambar 7 menunjukan metode uji coba, Dalam metode uji coba, Antena indoor dihubungkan dengan koneksi RF-input pada DVB-T2 STB. 2 output audio LR (Left and Right) pada AV-Out DVB-T2 STB dihubungkan ke audio input LR pada panel belakang televisi melalui koneksi AV-input. Sementara audio output LR pada AV-Out televisi dihubungkan dengan probe oscilloscope. Arah antenna diubah secara manual untuk mensimulasikan kondisi normal dan kondisi freeze. Gambar 8 menunjukan proses uji coba, sementara hasil uji coba ditunjukan pada Tabel 2.

Hasil uji coba menunjukan bahwa pada saat kondisi freeze, level audio pada kedua channel LR dalam kondisi flat. Sementara pada kondisi normal, level audio berubah sesuai dengan konten informasi. Hal ini menunjukan bahwa sinyal audio LR pada AV-Out DVB-T2 STB layak digunakan sebagai parameter tracking antenna system.

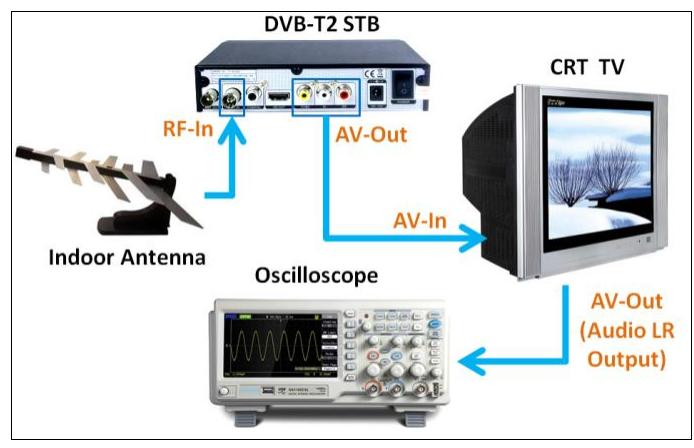

Gambar 7. Metode Uji Coba

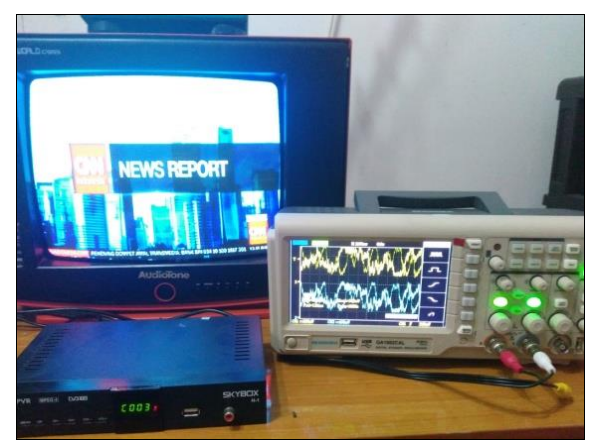

Gambar 8. Realisasi dan Proses Uji Coba 
Tabel 2. Hasil uji coba karakteristik sinyal audio

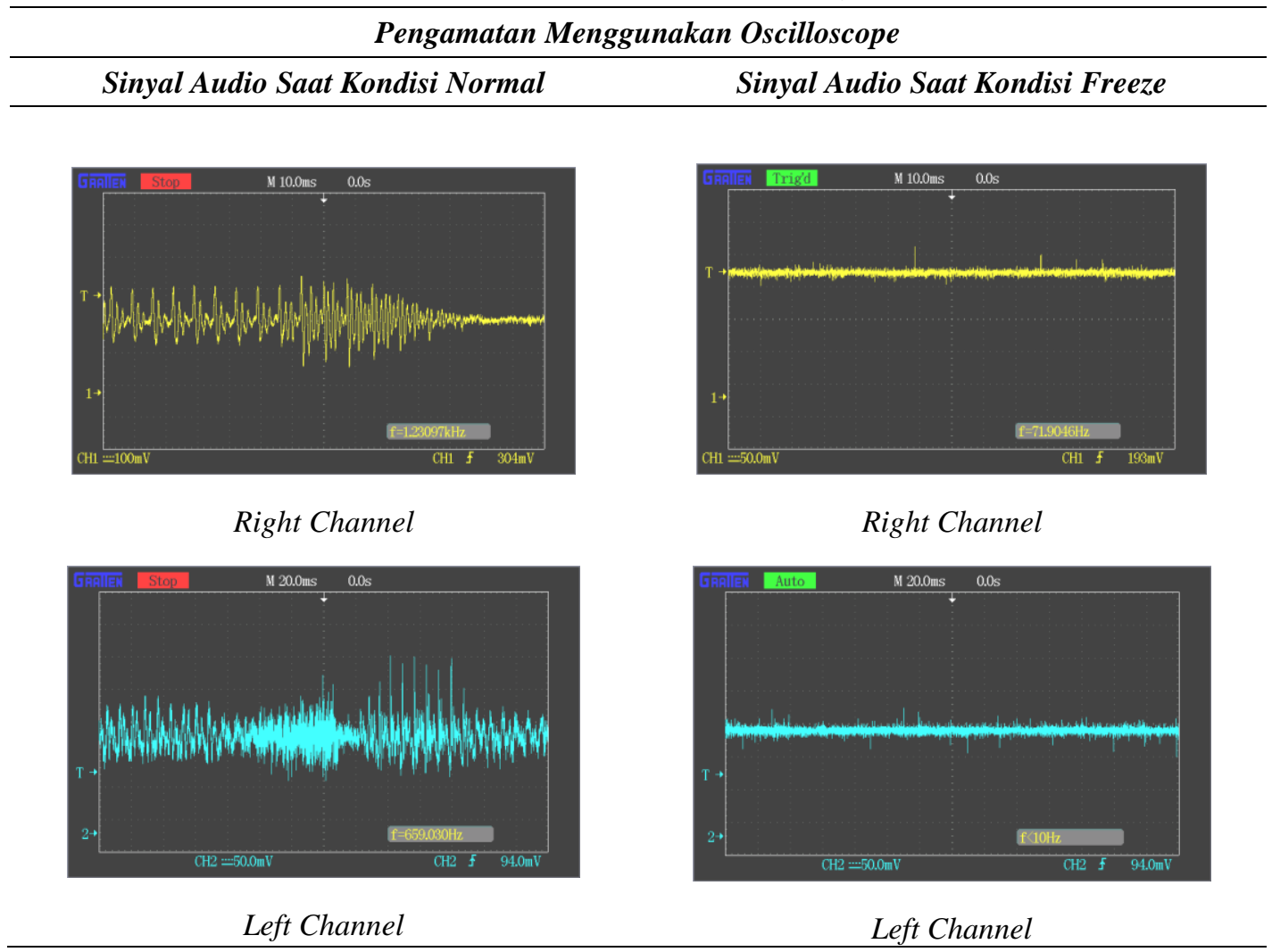

\subsection{Uji Kinerja Pemrosesan Sinyal}

Tujuan dari uji coba ini adalah untuk mengetahui karakteristik data pada blok pemrosesan sinyal analog audio dan video baik pada kondisi normal maupun kondisi freeze. Perbedaan karakteristik data saat kondisi freeze maupun normal digunakan sebagai acuan dalam menyusun algoritma pengambilan keputusan. Uji coba dilakukan dengan cara mengamati data pada 3 channel ADC. Gambar 9 menunjukan grafik hasil uji coba 3 channel ADC pada saat kondisi normal. Sementara Gambar 10 menunjukan grafik hasil uji coba 3 channel ADC pada saat kondisi freeze. Sumbu vertikal pada grafik adalah nilai kuantisasi ADC sementara sumbu horizontal adalah jumlah sampling. Sampling dilakukan sebanyak 20 kali dengan durasi antar sampling selama 1 detik.

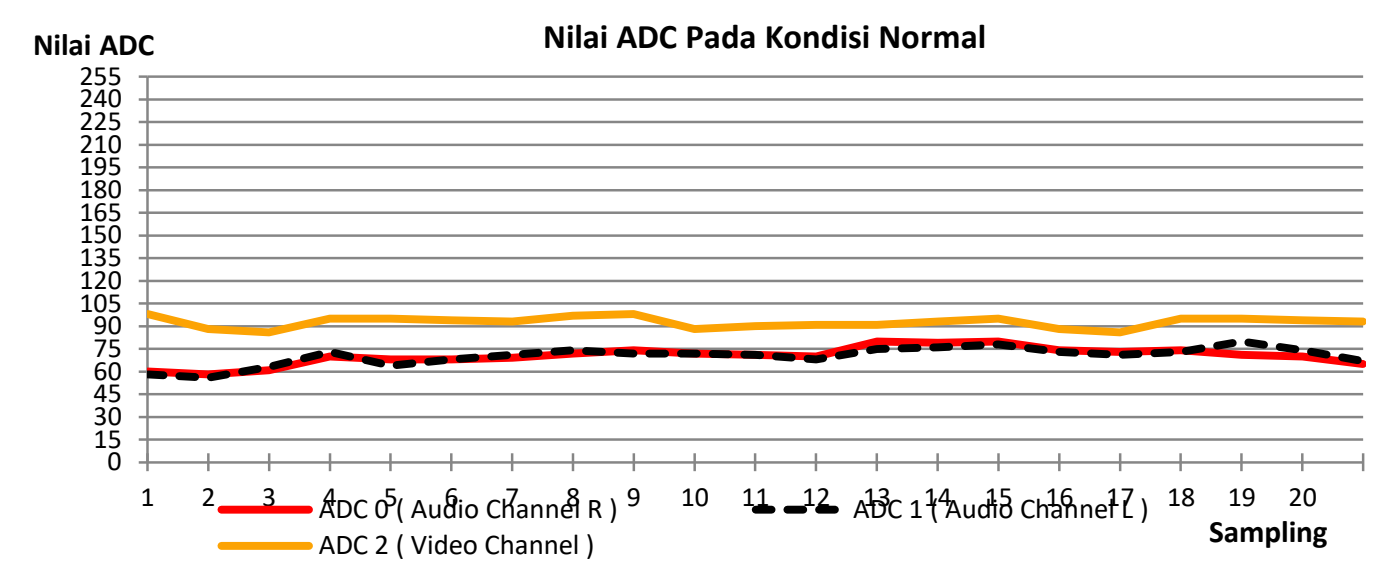

\section{Gambar 9. Uji Coba Saat Kondisi Normal}




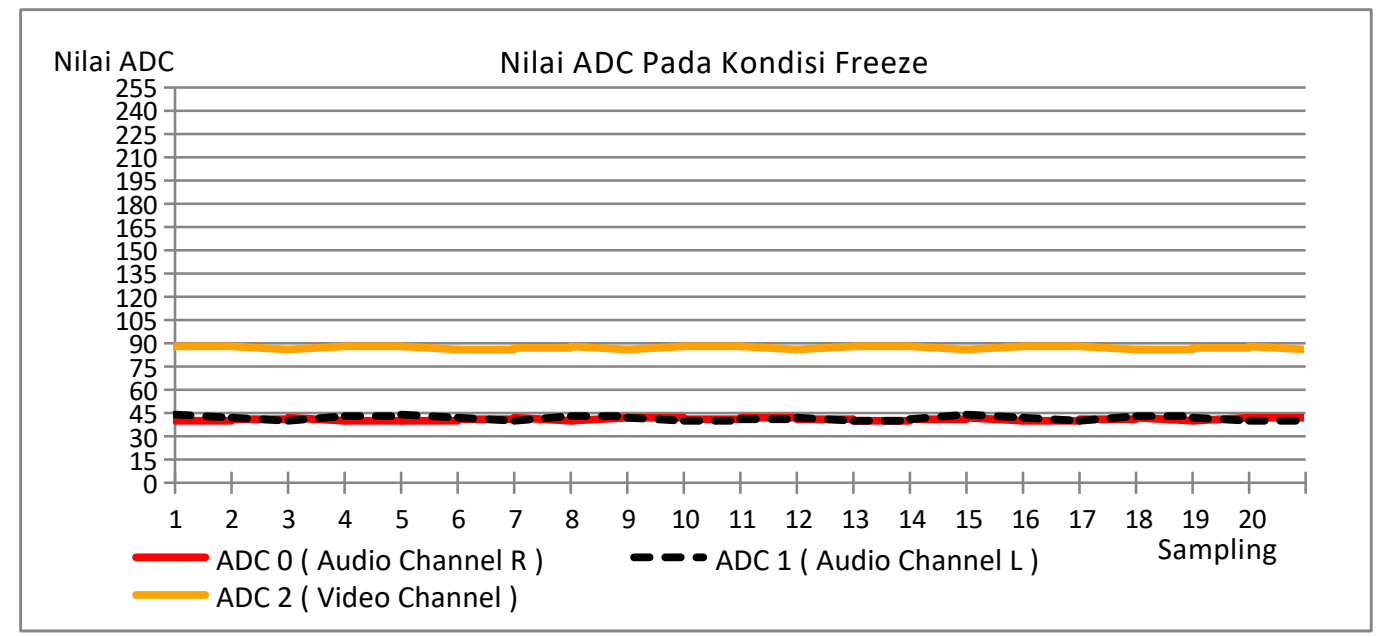

Gambar 10. Uji Coba Saat Kondisi Freeze

Jika kedua hasil uji coba dilakukan komparasi, maka dapat disimpulkan menjadi dua point penting. Hal pertama adalah, pada saat kondisi freeze, nilai ADC 2 (Video Channel) cenderung lebih flat. Sementara pada kondisi normal, nilai ADC 2 lebih berfariatif. Meskipun demikian, tidak ada perbedaan signifikan antara nilai ADC 2 (Video Channel) pada saat kondisi normal maupun freeze. Pada kedua kondisi, nilai ADC berkisar antara 88 hingga 98 pada skala kuantisasi ADC (0 hingga 255). Hal kedua adalah, saat kondisi freeze, nilai ADC 0 (Audio Channel $R$ ) dan ADC 1 (Audio Channel L) cenderung lebih flat. Sementara pada kondisi normal, nilai ADC 0 dan ADC 1 lebih berfariatif. namun ada perbedaan signifikan antara nilai ADC 2 (Video Channel) pada saat kondisi normal maupun freeze. Pada kondisi normal, nilai ADC berkisar antara 58 hingga 80. Sementara pada kondisi freeze, nilai ADC berkisar antara 40 hingga 44 pada skala kuantisasi ADC (0 hingga 255).

Dalam hal ini, berapapun nilai ADC bukanlah suatu hal yang penting karena hal itu dipengaruhi oleh tegangan offset pada hardware yang ada didalam blok audio video signal processing. Namun yang lebih dianggap penting adalah perbedaan nilai ADC saat kondisi normal maupun freeze. Dari uji coba ini, baik sinyal audio maupun sinyal video pada AV-Out DVB-T2 STB layak digunakan sebagai parameter input bagi tracking antenna system. Hal ini dapat dilihat dari perbedaan nilai ADC pada sinyal audio dan kestabilan nilai ADC pada sinyal video yang telah diukur dan dianalisa pada saat kondisi normal maupun freeze.

\section{KESIMPULAN}

Pada penelitian ini, sinyal audio dan video pada AV-Out STB digunakan sebagai parameter input bagi tracking antenna system. Sinyal audio dan video dikonversi menjadi data digital melalui ADC (Analog to Digital Converter). Pada pengolahan sinyal analog untuk audio, perbedaan nilai ADC pada kondisi normal maupun freeze menunjukan bahwa sinyal audio pada AV-Out DVB-T2 STB layak digunakan sebagai parameter bagi tracking antenna system. Begitu pula sebaliknya, pada pengolahan sinyal analog untuk video, variasi nilai ADC seiring perubahan waktu pada kondisi normal maupun freeze menunjukan bahwa sinyal video pada AV-Out DVB-T2 STB juga layak digunakan sebagai parameter input bagi tracking antenna system.

\section{UCAPAN TERIMA KASIH}

Ucapan terimakasih penulis sampaikan kepada Direktorat Riset dan Pengabdian Masyarakat (DRPM), Direktorat Jenderal Penguatan Riset dan Pengembangan, Kementerian Riset, Teknologi, dan Pendidikan Tinggi Republik Indonesia (KEMENRISTEK DIKTI) atas dukungan Pendanaan Penelitian Tahun Anggaran 2018 pada Skema Penelitian Kerjasama Antar Perguruan Tinggi (PEKERTI) yang dilaksanakan oleh Universitas Bhayangkara Surabaya (UBHARA) dengan Institut Teknologi Sepuluh Nopember (ITS) Surabaya, dengan nomor kontrak penelitian: 009/SP2H/LT/K7/KM/2018, pada tanggal 26 Februari 2018. Ucapan terimakasih juga penulis sampaikan kepada Pusat TIK dan Robotika ITS, dan Laboratorium Teknik Elektro UBHARA Surabaya. 


\section{DAFTAR PUSTAKA}

[1] H. Asjadi, "Smart antenna-aided indoor reception of digital terrestrial TV: Test \& development platform," IEEE Int. Symp. Broadband Multimed. Syst. Broadcast. BMSB, vol. 2014, no. 0, pp. 1-6, 2014.

[2] C. C. Wang, G. N. Sung, J. Y. Liao, J. Chang, and R. Hu, "Handheld DVB-T Digital TV with an automatic antenna selection method for mobile reception," Dig. Tech. Pap. - IEEE Int. Conf. Consum. Electron., pp. 24-25, 2007.

[3] A. A. A. El-Banna, M. El-Sabrouty, and A. Abdelrahman, "VHDL implementation of adaptive control unit in CIR-based adaptive K-best sphere decoder for DVB-T2," 2013 IEEE Faibl. Tens. Faibl. Consomm. FTFC 2013, no. Ml, pp. 0-3, 2013.

[4] A. A. A. El-banna and M. El-sabrouty, "CIR-based Adaptive K-Best Sphere Decoder for," pp. 615618, 2013.

[5] H. Miawarni and E. Setijadi, "Antenna tracking system based on pulse of synchronization CVBS: Design System and Analyze," Proc. - 2016 Int. Electron. Symp. IES 2016, pp. 228-233, 2017. 